\title{
Inferior oncological prognosis of surgery without oral chemotherapy for stage III colon cancer in clinical settings
}

\author{
Jo Tashiro*, Shigeki Yamaguchi, Toshimasa Ishii, Asami Suzuki, Hiroka Kondo, Yohei Morita, Kiyoka Hara \\ and Isamu Koyama
}

\begin{abstract}
Background: Cancer patients not admissible for adjuvant chemotherapy are generally at high risk of considerably inferior prognosis. The aim of this retrospective study was to evaluate poorer survival without administration of oral adjuvant chemotherapy of stage III colon cancer patients in clinical settings.

Methods: Between April 2007 and September 2011, 259 patients with stage III colon cancer who underwent curative surgery were retrospectively assigned to the adjuvant chemotherapy group of 171 patients (66\%) and the surgery alone group of 88 patients. Oral fluorouracil (5-FU) derivatives used in adjuvant chemotherapy, such as oral uracil and tegafur plus leucovorin (UFT/LV) or capecitabine, were the most commonly used.

Results: The 3-year relapse-free survival (RFS) rates were $74.9 \%$ for all cases, 58.3\% for the surgery alone group, and $83.4 \%$ for the adjuvant chemotherapy group $(P=0.0001)$. The chemotherapy group was associated with a dramatic improvement in survival for stage IIIB (surgery alone $57.7 \%$ versus adjuvant chemotherapy $83.9 \% ; P=0.0001$ ) and stage IIIC (surgery alone 18.2\% versus adjuvant chemotherapy 57.3\%; $P=0.006$ ) patients. There was a significant difference in the overall recurrence rate between groups (surgery alone 35.2\% versus adjuvant chemotherapy $18.1 \% ; P=0.002$ ). Multivariate analysis identified adjuvant therapy as an independent predictive factor of reduced recurrence (hazard ratio (HR): 3.231; $P=0.004$ ) and improved RFS (HR: $2.653 ; P=0.001$ ).

Conclusion: In clinical settings, adjuvant therapy was the only significant prognostic factor of survival. Since many patients prefer not to receive chemotherapy, it is critical to inform stage III colon cancer patients that chemotherapy raises their chances of survival by three-fold compared with curative surgery alone.
\end{abstract}

Keywords: Oral adjuvant chemotherapy, Colorectal cancer, Relapse-free survival, Overall survival, Capecitabine, Tegafur plus leucovorin

\section{Background}

Adjuvant chemotherapy after curative resection for stage III colon cancer patients has been widely recommended as a standard treatment to prolong disease-free survival (DFS) and overall survival (OS) since the early 1990s [1,2]. The National Surgical Adjuvant Breast and Bowel Project (NSABP) reported the results of a surgical adjuvant clinical trial (protocol C-03) that indicated significant extension of DSF and OS in stage II and III colon cancer patients who received fluorouracil (5-FU) plus leucovorin

\footnotetext{
* Correspondence: tashiro@saitama-med.ac.jp

Department of Gastroenterological Surgery, Saitama Medical University International Medical Center, Yamane, Hidaka-shi, Saitama 350-1298, Japan
}

(LV) compared with patients who received semustine, vincristine, and 5-FU (protocol C-04) [3-5]. Furthermore, the NSABP protocol C-06 demonstrated that oral uracil and tegafur (UFT) plus LV (UFT/LV) were associated with DSF and OS rates similar to those obtained with a regimen of intravenous weekly bolus 5 -FU plus LV (5-year DFS 67.0\% versus 68.2\%, 5-year OS 78.5\% versus 78.7\%) [6-8]. 5-FU significantly improves DFS and OS rates over surgery alone, with relative risk reductions of $30 \%$ and $26 \%$, respectively [9].

The Xeloda ${ }^{\circ}$ in Adjuvant Colon Cancer Therapy (XACT) trial was undertaken to compare the efficacy and tolerability of oral capecitabine with 5-FU/LV (intravenous 
bolus) as adjuvant therapy for patients with stage III colon cancer $[10,11]$. The 3 -year relapse-free survival (RFS) rates were $65.5 \%$ with capecitabine and $61.9 \%$ with $5-\mathrm{FU} / \mathrm{LV}$, for an absolute difference of $3.6 \%$ (95\% $\mathrm{CI},-0.9$ to $8.1 ; P=0.12$ ). The 3 -year OS rates were $81.3 \%$ with capecitabine and $77.6 \%$ with $5-\mathrm{FU} / \mathrm{LV}$, giving an absolute difference of $3.7 \%$ ( $95 \% \mathrm{CI},-0.1$ to $7.5 ; P=0.05$ ) between treatment groups. Since oral capecitabine offers equivalent clinical benefits in terms of efficacy, safety, convenience, and treatment cost, it can replace intravenous 5$\mathrm{FU} / \mathrm{LV}$ in the adjuvant treatment of stage III colon cancer.

Generally, patients not receiving adjuvant chemotherapy have considerably inferior prognosis. The Japanese Society for Cancer of the Colon and Rectum (JSCCR) reported recurrence rates of $30.8 \%$ for stage III colon cancer [12]. The present retrospective study evaluated the prognosis of stage III colon cancer patients excluded from adjuvant chemotherapy because they were older patients, had a high risk of severe comorbidities, or simply refused to receive treatment.

The limitations of the study are that it has retrospective clinical observations, a lack of patient randomization, and a dependence on the information available in the patient files. Which is more benefit or more harm associated with various treatment strategies is decided depending on the situation of each patients in clinical settings. Therefore, the aim of this study was to demonstrate the poor prognosis without oral adjuvant chemotherapy for stage III colon cancer patients in clinical settings.

\section{Patients and methods}

\section{Patient selection criteria}

Between April 2007 and September 2011, 259 patients with stage III colon cancer who underwent curative surgery were retrospectively assigned to the adjuvant chemotherapy group $(n=171)$ or the surgery alone group $(n=88)$. The database contained detailed information on patient characteristics, operative findings, histology, laboratory findings, and adjuvant therapies. The follow-up survival data were collected retrospectively through medical record analyses. The exclusion criteria were as follows: rectal cancer; malignancy other than colon cancer; and patients who did not receive adjuvant chemotherapy or did not have any information about the chemotherapy. Cancer was staged using the American Joint Committee on Cancer (AJCC) 7th edition TNM classification: colon and rectum [13].

\section{Chemotherapy adjuvant regimens}

All patients started receiving adjuvant $\geq 8$ weeks after curative surgery. They were required to have an Eastern Cooperative Oncology Group (ECOG) performance status of 0 to 2, to have signed informed consent, and be aged between 20 and 80 years old. The JSCCR recommends four adjuvant therapy regimens for stage III colorectal cancer: intravenous 5-FU/LV, UFT/LV, capecitabine, or FOLFOX (5-FU/LV plus oxaliplatin). In Japan, given the expected benefits and possible risks of toxicity, a consensus has not been reached as to whether adjuvant regimens containing oxaliplatin should be given to stage III patients. Several oral 5-FU derivatives are available, such as oral UFT/LV or capecitabine, and they are preferred for their convenience. Consequently, these were the most commonly used regimens in this study [14].

The UFT regimen is a preparation of tegafur-uracil in a molar ratio of 1:4. Tegafur is the 5-FU prodrug converted to 5 -FU in the liver. $\mathrm{LV}$ is used to modulate 5 -FU biochemically, and has been widely adopted for the treatment of advanced colorectal cancer $[8,15]$. The 5week cycles of chemotherapy consisted of 4 weeks of oral UFT/LV, followed by 1 week of rest, and were repeated for $\geq 6$ months. The UFT was administered at a dose of $300 \mathrm{mg} / \mathrm{m}^{2} /$ day, and LV was administered at a dose of $75 \mathrm{mg} /$ day. The daily doses of UFT/LV were divided into three doses administered every $8 \mathrm{~h}$ with water. Patients were instructed to avoid food from $1 \mathrm{~h}$ before to $1 \mathrm{~h}$ after each dose. Capecitabine is an oral fluoropyrimidine that generates 5 -FU preferentially in tumor tissue through a three-step enzymatic cascade [16]. The adjuvant was administered at a dose of $1.250 \mathrm{mg} / \mathrm{m}^{2}$ twice a day for 14 days, followed by 7 days of rest. Standard care included a total of eight cycles. The amount of drug received was based on reported pill counts and patient declarations at the end of each cycle.

\section{Follow-up protocol}

The patients were scheduled for follow-up visits every 3 months during the first 3 years, every 6 months during the next 2 years, and annually thereafter. Each visit included a physical examination and computed tomography $(\mathrm{CT})$ scans of the chest, abdomen, and pelvis. Colonoscopies were performed during the first, third, and fifth year of follow-up. The median follow-up period was 41 months (range: 3 to 73 months).

\section{Data analysis}

Statistical analysis was performed using SPSS version 21.0 software (SPSS Inc., Chicago, IL, USA). The chisquared test or Fisher's exact probability test were used to compare recurrence rates. Logistic regression analysis was conducted on the parameters found to be significantly associated with recurrence by chi-squared tests or Fisher's exact probability test $(P<0.05)$ to identify the independent factors of recurrence. Survival rates were calculated by the Kaplan-Meier method and compared by the log-rank test. Stepwise forward Cox regression model was conducted for parameters found to be significantly associated with survival by the log-rank test $(P<0.05)$ in order 
to identify the independent factors of survival. Values of $P<0.05$ were considered significant in all analyses. This analysis was conducted using the intention-to-treat theory.

\section{Results}

\section{Patient characteristics}

The two groups were similar with respect to gender, tumor location, depth of invasion, tumor differentiation and lymphovascular invasion, and TNM subclassification (IIIA/IIIB/IIIC) (Table 1). However, mean age was significantly higher in the surgery alone group (63.4 versus 75.4 years; $P<0.0001$ ). The causes for adjuvant chemotherapy rejection were older patients ( $>80$ years), high risk of severe comorbidities or postoperative complication, and self-judgment of refusal.

\section{Prevalence of each adjuvant regimen}

The UFT/LV regimen was performed in 104 patients (61\%), capecitabine in 59 patients (34\%), and other types in eight patients (5\%; S1 and single-agent of UFT). The overall compliance was $77 \%$, as 40 patients discontinued the therapy without evidence of a protocol event. The most common symptoms of drug toxicity were severe nausea and diarrhea (3.5\%); the risks of severe hepatitis, neutropenia, and hand foot syndrome (5\%) only with capecitabine. The completion rate of adjuvant chemotherapy was significantly less in patients with UFT/LV (72\%) than with capecitabine (83\%; $P<0.0001)$.

\section{Survival analysis}

The Kaplan-Meier estimates of 3-year OS and 3-year RFS survival are presented in Figure 1 and Figure 2, respectively. When the two groups were compared, the adjuvant chemotherapy was associated with a significant improvement in 3-year OS (surgery alone: $81.7 \%$ versus adjuvant chemotherapy: $93.5 \% ; P<0.001$ ) and RFS (surgery alone: $58.3 \%$ versus adjuvant chemotherapy: $83.4 \%$; $P<0.001)$. Furthermore, chemotherapy did not affect the 3 -year OS of stage IIIA and IIIC patients, and the 3-year RFS of stage IIIA patients.

Univariate and multivariate analyses were conducted for each clinicopathological factor (Table 2). Based on univariate analysis, advanced age was associated with poorer survival, whereas adjuvant chemotherapy was associated with improved survival. Multivariate analysis was performed to identify independent predictors of survival. Chemotherapy was the only significant prognostic factor of improved survival (hazard ratio (HR): 0.379; 95\% confidence interval $(\mathrm{CI}), 0.214$ to $0.670 ; P=0.001$ ), aside from oncological factors (depth of tumor invasion and TNM stage).

Cancer recurrence occurred in 62 patients (recurrence rate (rec rate), 23.9\%) during the follow-up period. The
Table 1 Comparison of patient characteristics stratified according to receipt of adjuvant chemotherapy and rejected reasons of adjuvant chemotherapy

\begin{tabular}{|c|c|c|c|}
\hline Variable & $\begin{array}{l}\text { Surgery } \\
(\mathrm{n}=\mathrm{88})\end{array}$ & $\begin{array}{c}\text { Adjuvant } \\
\text { chemotherapy }(n=171)\end{array}$ & $P$ value \\
\hline Gender & & & 0.78 \\
\hline Female & 38 & 77 & \\
\hline Male & 50 & 79 & \\
\hline Age (years, mean) & 75.4 & 63.4 & $<0.0001$ \\
\hline Comorbidity & $60(68 \%)$ & $82(47 \%)$ & 0.002 \\
\hline ASA (grade $\geq 3$ ) & $27(30 \%)$ & $2(1 \%)$ & $<0.0001$ \\
\hline \multicolumn{4}{|l|}{ Location } \\
\hline Right side of colon & 36 & 62 & 0.47 \\
\hline Left side of colon & 52 & 109 & \\
\hline Colon & 77 & 136 & 0.11 \\
\hline Rectosigmoid & 11 & 35 & \\
\hline \multicolumn{4}{|l|}{ Serum CEA } \\
\hline$\geq 5$ & $36(41 \%)$ & 73 (43\%) & 0.78 \\
\hline$\geq 10$ & $19(22 \%)$ & $43(25 \%)$ & 0.53 \\
\hline $\begin{array}{l}\text { Postoperative hospital } \\
\text { stay (mean) }\end{array}$ & 10.8 & 8.9 & 0.08 \\
\hline \multicolumn{4}{|l|}{ Histological type } \\
\hline Differentiated & 79 & 156 & 0.7 \\
\hline Undifferentiated & 9 & 15 & \\
\hline $\begin{array}{l}\text { Lymphovascular } \\
\text { invasion }(\geq 2,3)\end{array}$ & $26(30 \%)$ & $46(27 \%)$ & 0.65 \\
\hline \multicolumn{4}{|l|}{ Tumor depth } \\
\hline $\mathrm{T} 1 / \mathrm{T} 2 / \mathrm{T} 3 / \mathrm{T} 4$ & $13 / 5 / 52 / 18$ & $9 / 15 / 113 / 34$ & 0.06 \\
\hline \multicolumn{4}{|l|}{$\begin{array}{l}\text { Lymph node } \\
\text { metastasis }\end{array}$} \\
\hline N1 (1 to 3) & 65 & 131 & 0.33 \\
\hline $\mathrm{N} 2(4 \leq)$ & 23 & 40 & \\
\hline $\begin{array}{l}\text { Lymph node } \\
\text { number }(\geq 12)\end{array}$ & $81(92 \%)$ & 161 (94\%) & 0.52 \\
\hline \multicolumn{4}{|l|}{ TNM stage } \\
\hline$\|\mathrm{IA} /\| \mathrm{B} / \| \mathrm{I}$ & $16 / 60 / 11$ & $22 / 127 / 22$ & 0.380 \\
\hline \multicolumn{4}{|l|}{$\begin{array}{l}\text { Rejected reasons of } \\
\text { adjuvant chemotherapy }\end{array}$} \\
\hline $\begin{array}{l}\text { Older person } \\
\text { ( }>80 \text { years) }\end{array}$ & $37(42 \%)$ & & \\
\hline Self-judgment & $29(33 \%)$ & & \\
\hline $\begin{array}{l}\text { Severe } \\
\text { comorbidities }\end{array}$ & $16(18 \%)$ & & \\
\hline $\begin{array}{l}\text { Postoperative } \\
\text { complications }\end{array}$ & $6(7 \%)$ & & \\
\hline
\end{tabular}

ASA, American Society of Anesthesiologists physical status classification system; CEA, carcinoembryonic antigen; TNM, tumor, node, metastasis.

risk of recurrence during the first 3 years was two-fold higher for surgery alone (rec rate, 35\%) than with adjuvant chemotherapy (rec rate, 18\%). The overall median 

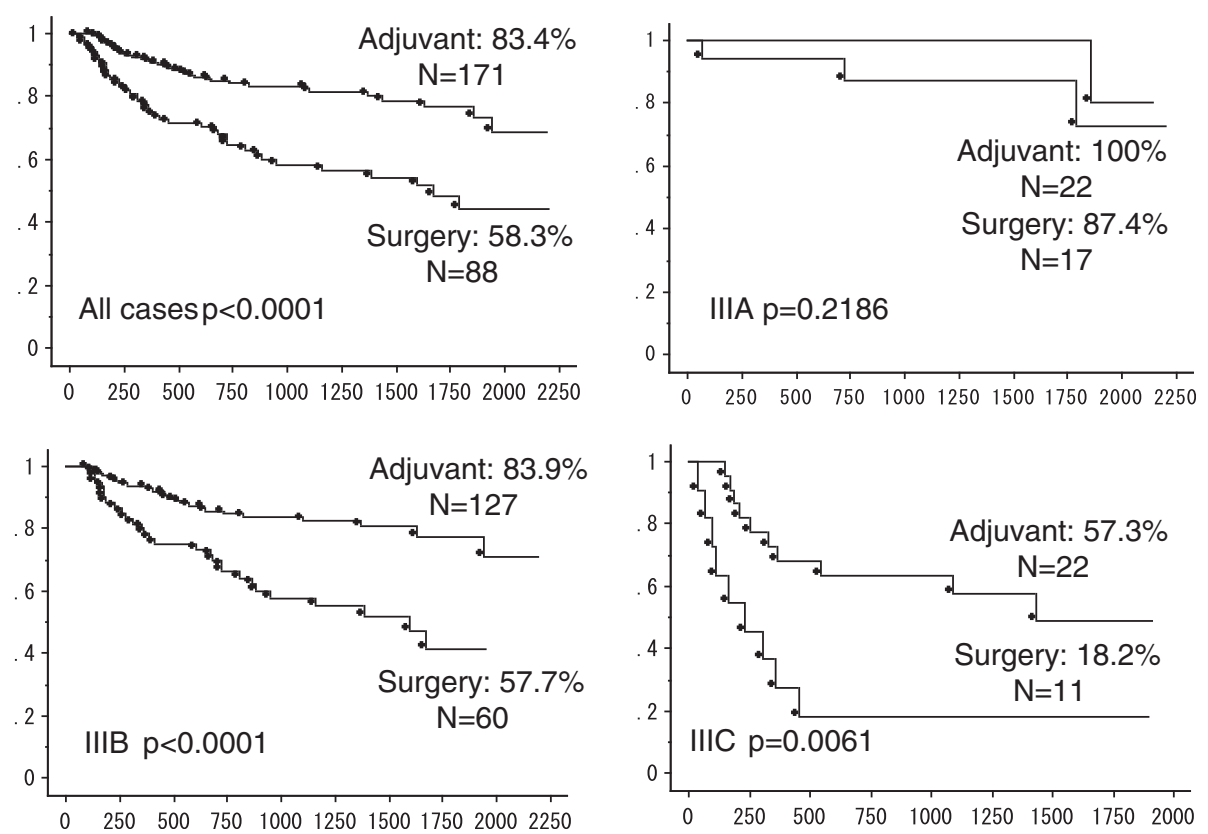

Figure 1 Kaplan-Meier estimates of 3-year relapse-free survival (RFS) of all cases, and patients with stage IIIA, IIIB, and IIIC colon cancer. Survival analysis compares the surgery alone group and chemotherapy group.

time to recurrence after initial resection for colon cancer was 10.5 months. In the surgery only group, the recurrence sites included the liver (12 patients, 38\%), lung (five patients, 16\%), dissemination (two patients, 6\%), local site (three patients, 10\%), and lymph node metastasis (four patients, 13\%). In the adjuvant chemotherapy group, the recurrence sites were the liver (seven patients, 22.5\%), lung (seven patients, 22.5\%), dissemination (seven patients, $22.5 \%$ ), local sites (one patient, 3\%), and lymph node metastasis (seven patients, $22.5 \%$ ).
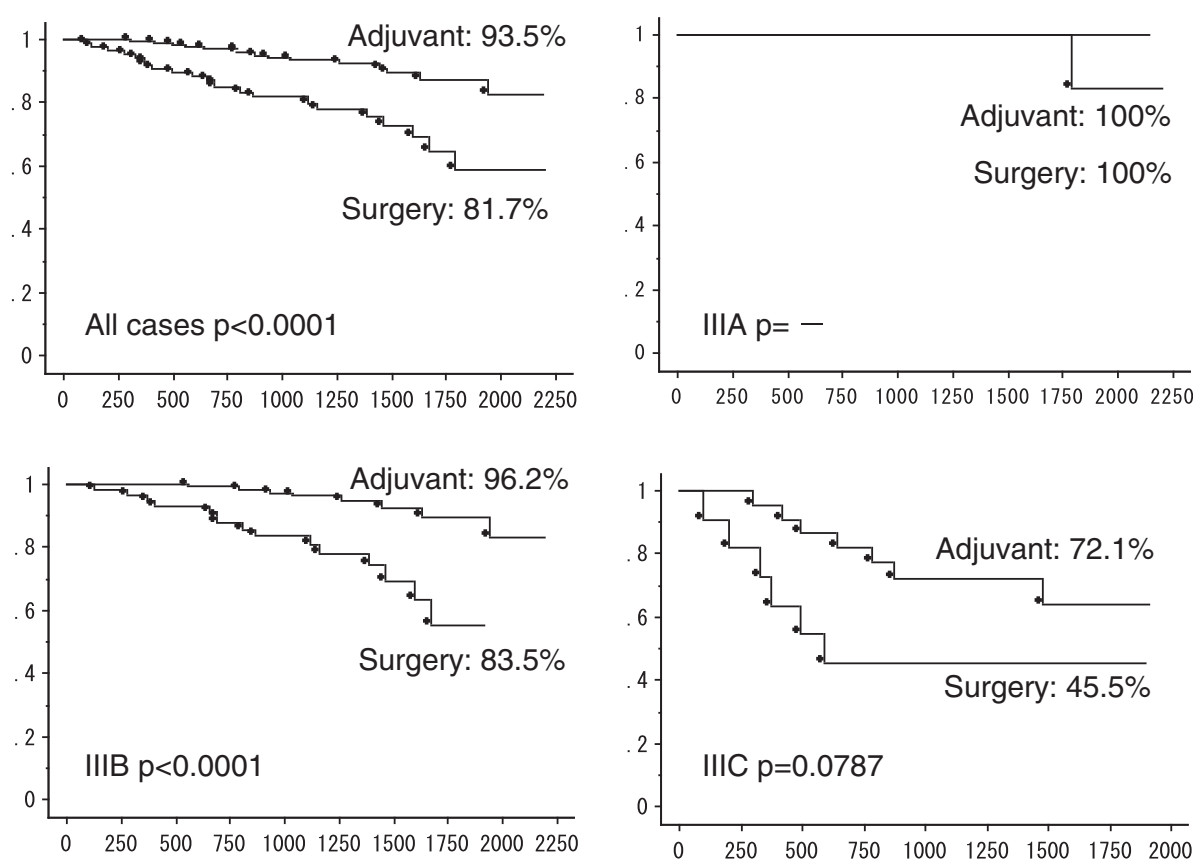

Figure 2 Kaplan-Meier estimates of 3-year overall survival (OS) of all cases, and patients with stage IIIA, IIIB, and IIIC colon cancer. Survival analysis compares the surgery alone group and chemotherapy group. 
Table 2 Univariate and multivariate regression analysis for relapse-free survival (RFS) of stage III colon cancer

\begin{tabular}{|c|c|c|c|c|c|}
\hline \multirow[t]{2}{*}{ Variable } & \multirow[t]{2}{*}{ Comparison } & \multirow{2}{*}{$\begin{array}{c}\text { Univariate } \\
P \text { value }\end{array}$} & \multicolumn{3}{|c|}{ Multivariate } \\
\hline & & & $\mathrm{HR}$ & $95 \% \mathrm{Cl}$ & $P$ value \\
\hline Gender & Female versus male & 0.24 & & & \\
\hline Age & & 0.001 & 1.01 & 0.986 to 1.043 & 0.324 \\
\hline Comorbidity & No versus yes & 0.745 & & & \\
\hline ASA (grade $\geq 3$ ) & No versus yes & 0.008 & 1.000 & 0.505 to 1.98 & 0.999 \\
\hline \multirow[t]{2}{*}{ Location } & Right versus left side of colon & 0.306 & & & \\
\hline & Colon versus rectosigmoid & 0.406 & & & \\
\hline Serum CEA & $<5$ versus $\geq 5$ & 0.074 & 0.84 & 0.519 to 1.366 & 0.49 \\
\hline Operation & Laparoscopic versus open surgery & 0.082 & 1.01 & 0.597 to 1.700 & 0.98 \\
\hline Tumor depth & $T 1,2$ versus $T 3,4$ & 0.002 & 0.26 & 0.089 to 0.733 & 0.01 \\
\hline Lymph node metastasis & N1 (1 to 3$)$ versus N2 $(4<)$ & 0.004 & 0.71 & 0.387 to 1.301 & 0.27 \\
\hline TNM stage & $\| \mathrm{A}, \mathrm{B}$ versus $\| \mathrm{C}$ & $<0.0001$ & 0.4 & 0.204 to 0.797 & 0.01 \\
\hline Adjuvant chemotherapy & No versus yes & $<0.0001$ & 2.65 & 1.48 to 4.756 & 0.001 \\
\hline
\end{tabular}

ASA, American Society of Anesthesiologists physical status classification system; $\mathrm{CEA}$, carcinoembryonic antigen; $\mathrm{Cl}$, confidence interval; HR, hazard ratio; TNM, tumor, node, metastasis.

Multivariate analysis was performed to identify independent predictive factors of recurrence (Table 3). Chemotherapy was the only significant predictive factor of recurrence (HR, 3.076; 95\% CI, 1.422 to $6.653 ; P=0.004$ ) apart from oncological factors (depth of tumor invasion and TNM stage).

\section{Discussion}

Recently, practice-based research (studies based on medical care) which got rid of the distance of a clinician and the researcher tends to be regarded as important [17]. It is a valuable study method that provides information from daily clinical situations. The present study provides the survival outcome of stage III colon cancer patients. We report that patients treated only by curative surgery for various reasons had considerably inferior prognosis than those receiving both surgery and chemotherapy. Oncologists are aware of this, but tend to disregard factors affecting the efficacy of adjuvant chemotherapy, such as age, comorbidity, and postoperative patient conditions. Cohort studies including these parameters would provide a more comprehensive analysis of cancer treatment outcome. For patients intolerant to anticancer drugs, cancer recurrence and prognosis due to aggravation of serious comorbidity are important factors influencing survival. The survival rates we present for surgery alone are more realistic because they account for the patients who refused chemotherapy for economic, social, or philosophical reasons.

The 3-year RFS rate of the surgery alone group was significantly lower than for the chemotherapy group. In addition, chemotherapy was associated with a two-fold

Table 3 Multivariate regression analysis for cancer recurrence of stage III colon cancer

\begin{tabular}{|c|c|c|c|c|}
\hline \multirow[t]{2}{*}{ Variable } & \multirow[t]{2}{*}{ Comparison } & \multicolumn{3}{|c|}{ Multivariate } \\
\hline & & HR & $95 \% \mathrm{Cl}$ & $P$ value \\
\hline Age & & 1 & 0.968 to 1.036 & 0.941 \\
\hline Comorbidity & No versus yes & 0.96 & 0.490 to 1.864 & 0.895 \\
\hline ASA (grade $\geq 3$ ) & No versus yes & 1.34 & 0.452 to 3.994 & 0.595 \\
\hline Location & Right versus left side of colon & 1.08 & 0.561 to 2.089 & 0.81 \\
\hline Serum CEA & $<5$ versus $\geq 5$ & 0.61 & 0.316 to 1.167 & 0.135 \\
\hline Operation & Laparoscopic versus open surgery & 1.08 & 0.503 to 2.301 & 0.85 \\
\hline Morbidity & No versus yes & 0.64 & 0.189 to 2.154 & 0.47 \\
\hline Tumor depth & $T 1,2$ versus $T 3,4$ & 0.17 & 0.037 to 0.801 & 0.03 \\
\hline Lymph node metastasis & N1 (1 to 3 ) versus N2 (4<) & 0.56 & 0.244 to 1.268 & 0.16 \\
\hline TNM stage & $\| I A, B$ versus IIIC & 0.29 & 0.106 to 0.785 & 0.02 \\
\hline Adjuvant chemotherapy & No versus yes & 3.23 & 1.458 to 7.159 & 0.004 \\
\hline
\end{tabular}

CEA, carcinoembryonic antigen; $\mathrm{Cl}$, confidence interval; $\mathrm{HR}$, hazard ratio. 
lower cancer recurrence rate during the first 3 years for stage III colorectal cancer patients, with $18 \%$ and $35 \%$, respectively. Both stage IIIB and IIIC patients benefited from chemotherapy with a dramatic improvement in survival rate over surgery alone. Multivariate analysis only identified chemotherapy as an independent predictive factor for improvements in prognosis and reduction in cancer recurrence. Therefore, patients unable or unwilling to receive chemotherapy have a poor oncological prognosis. It is critical to provide this information to the patients unable to receive adjuvant chemotherapy for stage IIIB and IIIC. When recurrence occurs in stage IIIB and IIIC colon cancer patients, the oncologic surgeon who makes the decision of surgery alone treatment will provide the best supportive care.

The present study emphasizes the needless of chemotherapy in cases of stage IIIA colon cancer. Whereas both groups had an excellent outcome, chemotherapy after surgery raised the 3 -year RFS from $87.4 \%$ to $100 \%$. While the sample sizes were too small to reach statistical significance, it is likely that chemotherapy could be omitted for certain types of stage IIIA colon cancer with low risk of recurrence, such as node positive T1/T2 patients. Adjuvant administration must be decided based on the status of each patient with stage IIIA colon cancer. While the benefits of 100\% 3-year RFS is important for patients, it must be weighed against the adverse effects.

We must determine how to improve the treatment of patients with poor performance status, severe comorbidities, and older patients who are not normally eligible for chemotherapy [18]. The older age patient group is commonly overlooked in clinical trials and, as a result, is often undertreated despite the proven efficacy of adjuvant therapy $[19,20]$. The X-ACT trial added to the growing volume of evidence suggesting that age alone should not be a barrier to the use of adjuvant chemotherapy in colon cancer $[21,22]$. On the other hand, performance status should be the governing factor. In addition, it is important to remember that renal impairment is more common in older patients, and is associated with an increased risk of toxicity with UFT/LV or capecitabine. Renal function should therefore be assessed before the onset of chemotherapy. The most appropriate type of chemotherapy requires a risk-benefit assessment of each adjuvant regimen available based on age, disease stage, performance status, comorbidities, and patient preference. For cancer patients hospitalized for severe comorbidities, an immunity activation agent (that is, polysaccharide-K) may be added to singleagent UFT, but the impact on recurrence has not been determined [23].

\section{Conclusion}

Although other reports have documented treatment outcomes in stage III colon cancer, the present study analyzed a rare subset of colon cancer patients (stage IIIA, IIIB, and IIIC) treated only with oral adjuvant chemotherapy at a single institution. Receiving adjuvant chemotherapy was the only prognostic factor for an improved treatment outcome in a clinical setting. Patients that are uncertain about the benefits of adjuvant chemotherapy should be informed of the poor survival rates for stage IIIB and IIIC colon cancer, as well as the excellent survival rates for stage IIIA colon cancer without adjuvant chemotherapy. Unfortunately, stage IIIB and IIIC colon cancer patients who cannot undergo adjuvant chemotherapy because of severe comorbidities, an advanced age, or by choice, need to be informed of the inferior prognosis without treatment.

\section{Abbreviations}

5-FU: Fluorouracil; AJCC: American Joint Committee on Cancer; ASA: American Society of Anesthesiologists physical status classification system; CEA: Carcinoembryonic antigen; Cl: Confidence interval; CT: Computed tomography; DFS: Disease-free survival; ECOG: Eastern Cooperative Oncology Group; HR: Hazard ratio; JSCCR: Japanese Society for Cancer of the Colon and Rectum; LV: Leucovorin; NSABP: National Surgical Adjuvant Breast and Bowel Project; OS: Overall survival; rec rate: Recurrence rate; RFS: Relapse-free survival; TNM: Tumor, node, metastasis; UFT: Uracil and tegafur; X-ACT: Xeloda in Adjuvant Colon Cancer Therapy.

\section{Competing interests}

The authors declare that they have no competing interests.

\section{Authors' contributions}

JT acted as guarantor of the integrity of the study, conceived the study concept, designed the study, defined the intellectual content, performed the literature research, undertook clinical and experimental studies, performed data acquisition, data analysis, and statistical analysis, and prepared and edited the manuscript. SY reviewed the manuscript. All authors read and approved the final manuscript.

\section{Acknowledgements}

This study was not funded by an outside source.

Received: 4 January 2014 Accepted: 29 April 2014

Published: 10 May 2014

\section{References}

1. Moertel CG, Fleming TR, Macdonald JS, Haller DG, Laurie JA, Goodman PJ, Ungerleider JS, Emerson WA, Tormey DC, Glick JH, Veeder MH, Mailliard JA: Levamisole and fluorouracil for adjuvant therapy of resected colon carcinoma. N Engl J Med 1990, 322(6):352-358.

2. $\mathrm{NIH}$ consensus conference: adjuvant therapy for patients with colon and rectal cancer. JAMA 1990, 264(11):1444-1450.

3. Wolmark N, Rockette H, Fisher B, Wickerham DL, Redmond C, Fisher ER, Jones J Mamounas EP, Ore L, Petrelli NJ: The benefit of leucovorin-modulated fluorouracil as postoperative adjuvant therapy for primary colon cancer: results from National Surgical Adjuvant Breast and Bowel Project protocol C-03. J Clin Oncol 1993, 11(10):1879-1887.

4. O'Connell MJ, Wolmark N, Yothers G, Haile S, Colangelo L, Petrelli N: Durable improvement in disease-free survival (DFS) and overall survival (OS) for stage II or III colon cancer treated with leucovorin-modulated fluorouracil (FL): 10-year follow-up of National Surgical Adjuvant Breast and Bowel Project (NSABP) protocol C-03. J Clin Oncol 2005, 23(1):248.

5. Wolmark N, Rockette H, Mamounas E, Jones J, Wieand S, Wickerham DL, Bear HD, Atkins JN, Dimitrov NV, Glass AG, Fisher ER, Fisher B: Clinical trial to assess the relative efficacy of fluorouracil and leucovorin, fluorouracil and levamisole, and fluorouracil, leucovorin, and levamisole in patients with Dukes' B and C carcinoma of the colon: results from National Surgical Adjuvant Breast and Bowel Project C-04. J Clin Oncol 1999, 17(11):3553-3559. 
6. Pazdur R, Lassere $Y$, Rhodes V, Ajani JA, Sugarman SM, Patt YZ, Jones DV Jr Markowitz AB, Abbruzzese JL, Bready B: Phase II trial of uracil and tegafur plus oral leucovorin: an effective oral regimen in the treatment of metastatic colorectal carcinoma. J Clin Oncol 1994, 12(11):2296-2300.

7. Saltz LB, Leichman CG, Young CW, Muggia FM, Conti JA, Spiess T, Jeffers S, Leichman LP: A fixed-ratio combination of uracil and Ftorafur (UFT) with low dose leucovorin. An active oral regimen for advanced colorectal cancer Adjuvant therapy for patients with colon and rectal cancer. Cancer 1995, 75(3):782-785.

8. Meguro M, Furuhata T, Okita K, Nishidate T, Ishiyama G, Iwayama Y, Kimura Y, Mizuguchi T, Hirata K: Clinical compliance with an oral uracil/tegafur (UFT) plus leucovorin (LV) regimen as adjuvant chemotherapy in Japanese colorectal cancer patients. Int J Clin Oncol 2009, 14(5):402-407.

9. Gill S, Loprinzi CL, Sargent DJ, Thomé SD, Alberts SR, Haller DG, Benedetti J, Francini G, Shepherd LE, Francois Seitz J, Labianca R, Chen W, Cha SS, Heldebrant MP, Goldberg RM: Pooled analysis of fluorouracil-based adjuvant therapy for stage II and III colon cancer: who benefits and by how much? J Clin Oncol 2004, 22(10):1797-1806.

10. Twelves C, Wong A, Nowacki MP, Abt M, Burris H 3rd, Carrato A, Cassidy J, Cervantes A, Fagerberg J, Georgoulias V, Husseini F, Jodrell D, Koralewski P, Kröning H, Maroun J, Marschner N, McKendrick J, Pawlicki M, Rosso R, Schüller J, Seitz JF, Stabuc B, Tujakowski J, Van Hazel G, Zaluski J, Scheithauer W: Capecitabine as adjuvant treatment for stage III colon cancer. N Engl J Med 2005, 352:2696-2704.

11. Scheithauer W, McKendrick J, Begbie S, Borner M, Burns WI, Burris HA, Cassidy J, Jodrell D, Koralewski P, Levine EL, Marschner N, Maroun J, Garcia-Alfonso P, Tujakowski J, Van Hazel G, Wong A, Zaluski J, Twelves C, X-ACT Study Group: Oral capecitabine as an alternative to i.v. 5-fluorouracil-based adjuvant therapy for colon cancer: safety results of a randomized, phase III trial. Ann Oncol 2003, 14(12):1735-1743.

12. Kobayashi H, Mochizuki H, Sugihara K, Morita T, Kotake K, Teramoto T, Kameoka S, Saito Y, Takahashi K, Hase K, Oya M, Maeda K, Hirai T, Kameyama M, Shirouzu K, Muto T: Characteristics of recurrence and surveillance tools after curative resection for colorectal cancer: a multicenter study. Surgery 2007, 141(1):67-75.

13. Edge S, Byrd DR, Compton CC, Fritz AG, Greene FL, Trotti A: Colon and rectum. In AJCC Cancer Staging Manual. 7th edition. New York, NY: Springer; 2010.

14. Mochizuki I, Takiuchi H, Ikejiri K, Nakamoto Y, Kinugasa Y, Takagane A, Endo T, Shinozaki H, Takii Y, Takahashi Y, Mochizuki H, Kotake K, Kameoka S, Takahashi K, Watanabe T, Watanabe M, Boku N, Tomita N, Matsubara Y, Sugihara K: Safety of UFT/LV and S-1 as adjuvant therapy for stage III colon cancer in phase III trial: ACTS-CC trial. Br J Cancer 2012, 106(7):1268-1273.

15. Kopec JA, Yothers G, Ganz PA, Land SR, Cecchini RS, Wieand HS, Lembersky BC, Wolmark N: Quality of life in operable colon cancer patients receiving oral compared with intravenous chemotherapy: results from National Surgical Adjuvant Breast and Bowel Project Trial C-06. J Clin Oncol 2007, 25(4):424-430.

16. Miwa M, Ura M, Nishida M, Sawada N, Ishikawa T, Mori K, Shimma N, Umeda I, Ishitsuka H: Design of a novel oral fluoropyrimidine carbamate, capecitabine, which generates 5 fluorouracil selectively in tumours by enzymes concentrated in human liver and cancer tissue. Eur J Can 1998, 34(8):1274-1281.

17. Mjör IA: Practice-based dental research. J Oral Rehabil 2007, 34(12):913-920.

18. Tashiro J, Yamaguchi S, Ishii T, Sato T, Suwa H, Okada I, Kondo H, Miyazawa M, Shinozuka N, Koyama I: A comparative study on the short-term clinical outcomes of laparoscopic versus open Hartmann's procedure for high risk patients in colorectal cancer. Hepatogastroenterology 2012, 59(117):1403-1407

19. Schrag D, Cramer LD, Bach PB, Begg CB: Age and adjuvant chemotherapy use after surgery for stage III colon cancer. J Natl Cancer Inst 2001, 93(11):850-857.

20. Jessup JM, McGinnis LS, Steele GD Jr, Menck HR, Winchester DP: The national cancer data base report on colon cancer. Cancer 1996, 78(4):918-926.

21. Sargent DJ, Goldberg RM, Jacobson SD, Macdonald JS, Labianca R, Haller DG, Shepherd LE, Seitz JF, Francini G: A pooled analysis of adjuvant chemotherapy for resected colon cancer in elderly patients. N Engl J Med 2001, 345(15):1091-1097.
22. Sundararajan V, Mitra N, Jacobson JS, Grann VR, Heitjan DF, Neugut Al: Survival associated with 5-fluorouracil-based adjuvant chemotherapy among elderly patients with node-positive colon cancer. Ann Intern Med 2002, 136(5):349-357.

23. Fisher $M$, Yang $L X$ : Anticancer effects and mechanisms of polysaccharide-K (PSK): implications of cancer immunotherapy. Anticancer Res 2002, 22(3):1737-1754

doi:10.1186/1477-7819-12-145

Cite this article as: Tashiro et al:: Inferior oncological prognosis of surgery without oral chemotherapy for stage III colon cancer in clinical settings. World Journal of Surgical Oncology 2014 12:145.

\section{Submit your next manuscript to BioMed Central and take full advantage of:}

- Convenient online submission

- Thorough peer review

- No space constraints or color figure charges

- Immediate publication on acceptance

- Inclusion in PubMed, CAS, Scopus and Google Scholar

- Research which is freely available for redistribution

Submit your manuscript at www.biomedcentral.com/submit
C BioMed Central 